\title{
Possibilities of the Additional Damping of Unidirectional Fiber Composites by Implementation of Viscoelastic Neoprene and Rubber Layers
}

\author{
Petr Kulhavy, Michal Petru, and Martina Syrovatkova \\ Institute for Nanomaterials, Advanced Technologies and Innovation, Technical University of Liberec, \\ Studentska 2, 46117 Liberec 1, Czech Republic
}

Correspondence should be addressed to Petr Kulhavy; petr.kulhavy@tul.cz

Received 23 May 2017; Revised 11 July 2017; Accepted 16 July 2017; Published 7 September 2017

Academic Editor: Abdollah Shafieezadeh

Copyright (C) 2017 Petr Kulhavy et al. This is an open access article distributed under the Creative Commons Attribution License, which permits unrestricted use, distribution, and reproduction in any medium, provided the original work is properly cited.

\begin{abstract}
The aim of the presented work is to assess modal, transmission, and damping characteristics of layered carbon plates. The base is to carry experimental analysis verified by FEM model, which evaluates the vibration transfer of tested composites and describes possibilities of additional damping by implementation of viscoelastic layers. Preimpregnated carbon fibers known as prepreg were used for creation of the samples composed of four ( 2 constant and 2 variable) layers. The task was to assess impact of changing the fiber orientation on the transfer function and individual modal characteristics. As another option, testing of some additional damping materials was included. Neoprene and thin rubber coat were added as an outside damping element when the neoprene ply was inserted also among the layers. Expected dependence of the plies orientation onto the shape of the transfer function and even swapping of some of MOD characters (bending, torsion, and their combinations) have been found. The use of the additional damping materials is also possible but the right combination of the individual plies layout and stacking sequence is the most significant part. The results had been statistically analyzed and showed that the created layered shell FE models could be used to describe the behavior.
\end{abstract}

\section{Introduction}

Nowadays, development of composite materials and optimization of their properties have important position in all industrial sectors. Constructions based on long fiber composites gained significant and irreplaceable position through almost all traffic sectors especially because of their potential to target a variety of material properties to suit actual needs [1]. Long fibers reinforced composites offer generally the greatest flexibility of mechanical and other properties. Knowledge of the basic mechanical properties is the most fundamental factor for the precise modeling and prediction of the final parts properties as well as knowledge of the vibration response, damping characteristics, and possibility of their modification by varying composition of the individual plies. Damping of the vibration is usually used to improve product performance, especially its durability in terms of avoiding their using in the resonant frequencies. The use of advanced materials has gained wide acceptance in the last few decades. Compared to metallic structures, composite laminates offer some unique engineering properties while presenting interesting and challenging problems for analysts and designers [2]. The main sought dependencies are the transfer function, modal characteristics, and structural damping in dependency on the angle of the individual layers. In real cases it is possible to produce and find almost unlimited combinations of individual layers. Another important requirement is to specifically target the resulting synergistic effect; this means the significant anisotropy of the materials, considering, for example, a direction of the real load as can be seen in Figure 1. For accurate description of layered composite structures, their internal layout and their behavior must be accurately predicted and carefully monitored. The material properties determined from standard specimens tested in laboratory often significantly deviate from properties of components manufactured in factory $[3,4]$. The important features in the field of mechanical design are energy dissipation in structures and requirements 




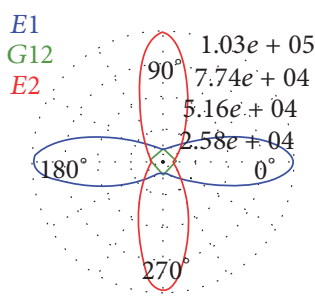

$0 / 0 / 0 / 0$

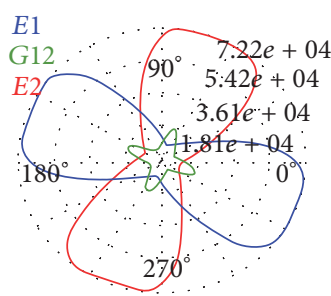

$0 / 45 / 0 /-45$

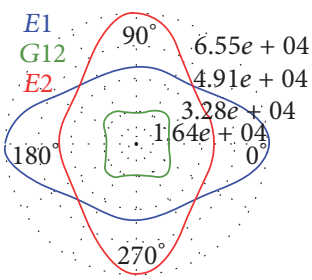

$0 / 60 / 0 /-60$

FIgURE 1: The base coordinate and basic material characteristics of some tested samples.

to reduce the amplitudes of vibrations. For fiber-reinforced composite materials, the material damping is high and it depends on the materials constitution [5]. In the reduction of the vibration, we usually would like to improve parameters of created devices including their durability and eliminate resonance at the range along the operating frequency of the device. The second target of this article is to assess properties modified by adding some viscoelastic layers in order to improve the damping characteristics of tested materials. With this idea of additional layers $[5,6]$, a nonlinear superposition method was used for the creation of models and the behavior of laminates with interleaved viscoelastic layers was subsequently experimentally evaluated. Fiber-reinforced composites are induced by different processes such as the viscoelastic behavior of matrix and the damping at the fibermatrix interface. At the laminate level, damping depends on the constituent layers properties as well as their orientations, interlaminar effects, stacking sequence, and so on. The use of modern advanced composite materials has gained wide acceptance over the last few decades because of their high strength-to-weight and stiffness-to-weight ratios. Compared to metallic structures, composite laminates offer some unique engineering properties while presenting interesting but challenging problems for analysts and designers. Authors [7-10] compared the vibration characteristics of steel and composite materials and pointed to relatively small damping in metal materials. This leads to significant amplitudes of vibration. Damping in fibers reinforced materials is much higher and significantly depends on the material composition. Metal materials are characterized by their isotropy whereas the long fiber composite materials have modulus of elasticity for the relevant axis always dependent on the orientation of all layers constituting the laminate. Lepoittevin [6] mentioned advantages of using composite materials, for example, the fact that the damping rate of a glass fiber beam is almost five times larger than the one of an aluminum beam. However, the question is how they were compared, whether with the same mass, rigidity, or just volume (easily) which is not the decisive factor. Frequent imprecision of some producers or authors is to try to compare different materials. It is possible to find studies of specimens having the same shape but not having equal weight and stiffness. That is why the direct comparison of mutual results is not possible. It is always necessary to compare samples with identical mass and stiffness or like in our case use the relative parameter, structural damping ratio. Bena et al. [10] studied methodology for finding material damping properties at higher frequency and at relatively lower amplitudes. Kyriazoglou and Guild [11] used the finite element method for prediction and comparison of the damping characteristics of carbon and glass fiber-reinforced polymers (CFRP, GFRP) laminates. Zou et al. [12] tried to identify some delaminated zones based on the vibration response. Saravanos [13] investigated the integrated damping for composite plates with constrained interlayers of polymer materials. Yim and Gillespie [14] studied dependency of the loss factor on the length/thickness ratio for free clamped laminated plates. Plagianakos and Saravanos [15] described the sensitivity of entire response on the individual plies orientation. They used a term, so-called passive damping, and marked it as the critical parameter for improving dynamic performance of flexible structures from the point of view of fatigue, aeroelastic stability, and accurate positioning of some specific devices and sensors in micromechanics. Lee and Kosmatka [16] developed discrete-layer triangular elements used for predicting damping in composite plates, including higher order terms in the displacement approximation through the thickness, and presented experimental results for composite plates with an interlaminar damping layer. Birman and Byrd [17] based on free vibration studied the loss factor of orthotropic materials and this way created models implemented into a sandwich structures. Lepoittevin [6] studied the structural damping ratio of UD composites and also emphasized that there is a big advantage in using the inner viscoelastic layers regarding bending stability, stiffness, and also buckling properties. Sepahvand [7] emphasized that the viscoelastic properties of the polymeric matrix and the damping of the FRC are several orders of magnitude higher than those for the conventional materials. However, increasing the matrix volume has contrast impact on the structure stiffness and strength. In his study, the thermoplastic matrices that exhibit higher damping levels were compared also to thermoset ones. Pritz [18] based on the Kramers-Kronig dispersion relations studied the causality requirement for the dynamic modulus as a function of frequency from the loss modulus. He also emphasized that the frequency dependence of the dynamic modulus obeys the power law of the same type as the loss modulus and that the coefficients in these frequency functions are interrelated. Talbot and Woodhouse [19] had tried to describe whether the laminate theory could be inverted in order to obtain the ply properties directly from the experimental results. Furthermore they tried to verify whether the approach with thin plate could predict 
the low frequency vibration with sufficient accuracy. They also emphasized that the elastic constants are very sensitive to variations during the manufacturing process. Canor et al. [20] studied behavior of dynamic systems based on modal characteristics with added virtual loadings. They also mentioned that, with an assumption that the structural damping is proportional, the modal transfer matrix is diagonal and the inversion operation is trivial and straightforward. Morzfeld et al. [21] computationally and theoretically studied level of errors that arose due to the decoupling approximation and mentioned that a common procedure, termed the decoupling approximation, is to ignore these off-diagonal elements if they are small enough. This does not mean, however, that errors due to the decoupling approximation are minimized. Finally quite similar research like that in our article is the one by Kishi et al. [8] who studied the damping properties of carbon fiberreinforced epoxy composites by the mechanical impedance method. He used several types of thermoplastic-elastomer films, such as polyurethane elastomers and polyethylenebased ionomers as the interleaving materials.

\section{Materials and Methods}

The basic, simplest, and simultaneously the most complex way that takes into account the entire spectrum of submechanic parameters for mutual comparison seems to be the vibration test, namely, modal and response analysis. The value of natural frequencies and found damping characteristics could show us the interrelationship of the basic mechanical parameters of the two compared methods. Experimental and analytical characterization of damping is not easy, even with conventional structural materials, and the anisotropic nature of composite materials makes it even more difficult. The techniques for damping measurement often deal with natural frequency or resonant frequency of the system. In general, all apparatus for the investigation of vibration can be categorized as free vibration or forced vibration. Free vibration is a system with absence of any external input except the initial impulse of displacement and velocity [22]. For the forced vibration a periodic exciting force or a random noise is applied to the structure. Typical forced vibration techniques include the free-free beam technique and the piezoelectric ultrasonic composite oscillator technique [23]. Material damping represents the cumulative contributions of the viscoelastic response of the constituents, cyclic heat flow, and friction at the fiber/matrix interface. Materials with internal interfaces, as indicated by the interfaces of the laminate of conventional composite materials, can dissipate mechanical energy through the movement of the interface by mechanisms such as a discontinuity of stress across the interface or by friction losses [14].

2.1. Theory. Composite materials fall into two categories: fiber-reinforced and particle-reinforced (or whiskerreinforced) materials. Both are widely used in advanced structures. In engineering applications among all of the various kinds of composites, glass fiber-reinforced polymers (GFRP) and carbon fiber-reinforced polymers (CFRP) become important due to their acceptable cost, light weight, high specific strength, and good corrosion resistance. Plastic materials reinforced by long fibers are widely used because of their high strength and modulus to density ratio. Long carbon fibers or fabrics which are preimpregnated with resin are called prepregs. For this, unidirectional material is the longitudinal Young's modulus in comparison with the transverse one which significantly lower. By using the "rule of mixtures," it is possible to estimate longitudinal modulus of each ply in unidirectional long fiber composite with formula (1). In Figure 1 there is comparison of $E_{1}, E_{2}$, and shear modulus at the plane $12, G_{12}$ for three tested samples at different direction of two plies and equal direction of the last two.

$$
\begin{aligned}
\left\{\begin{array}{l}
\varepsilon_{11} \\
\varepsilon_{22} \\
\varepsilon_{33} \\
\gamma_{12} \\
\gamma_{23} \\
\gamma_{13}
\end{array}\right\}= & {\left[\begin{array}{cccccc}
\frac{1}{E_{11}} & \frac{-v_{12}}{E_{11}} & \frac{-v_{12}}{E_{11}} & 0 & 0 & 0 \\
\frac{-v_{12}}{E_{11}} & \frac{1}{E_{22}} & \frac{-v_{23}}{E_{22}} & 0 & 0 & 0 \\
\frac{-v_{12}}{E_{11}} & \frac{-v_{23}}{E_{22}} & \frac{1}{E_{22}} & 0 & 0 & 0 \\
0 & 0 & 0 & \frac{1}{G_{23}} & 0 & 0 \\
0 & 0 & 0 & 0 & \frac{1}{G_{12}} & 0 \\
0 & 0 & 0 & 0 & 0 & \frac{1}{G_{12}}
\end{array}\right] } \\
& \cdot\left\{\begin{array}{l}
\sigma_{11} \\
\sigma_{22} \\
\sigma_{33} \\
\tau_{12} \\
\tau_{23} \\
\tau_{13}
\end{array}\right\},
\end{aligned}
$$

where for a transversal isotropic composite $\sigma_{i i}, \varepsilon_{i i}$ are the main stress and strains in the direction of the individual axes of the main coordinate system $x_{1}, x_{2}, x_{3}$, when also $\sigma_{11}>\sigma_{22}=\sigma_{33}$ and $\varepsilon_{11} \neq \varepsilon_{22}=\varepsilon_{33} . \tau_{12}, \tau_{23}=\tau_{13}$ are the shear stresses in the respective planes, $\gamma_{12}, \gamma_{23}=\gamma_{13}$ expresses the bevel relative to the individual planes, $E_{11}, E_{22}=E_{33}$ express the longitudinal and transverse modulus of elasticity, $G_{12}, G_{23}$ are the shear moduli in the plane of the main loading direction and in the plane perpendicular to the main loading direction, $v_{12}$ is the Poisson number in the direction of plane of the main load, and $v_{23}$ is the Poisson number in a plane perpendicular to the main loading direction.

2.2. Models for Study of Mechanical Properties of Unidirectional Fiber Composites. The prediction of the mechanical properties of the transverse isotropic composite has been part of many researches [24-36] and studies in the past, and it is also the subject of research at present, where most of the studies show that, for the integrated values, it depends on the knowledge of all elastic constants entering the model according to (1). It should be noted that these elastic constants are generally different for each type of composite, 
and therefore it is difficult to determine all the constants through the analytical models. Due to this fact, especially in the past in the design of composite structures, some of these constants were neglected and obtained subsequently through their direct measurement. Over time, some of the analytical relationships have been expanded upon and now the comprehensive approach exists. Based on this approach it is possible to obtain all elastic constants through the following models:
(i) Phenomenological models
(ii) Semiempirical models
(iii) Homogenized models
(iv) Flexible-elastic models.

Phenomenological models were created in the past for a primary mathematical derivation of the mechanical properties of transversally isotropic fibrous composite structures, but they could be used sufficiently well also in this day. Such models are the Voigt and Reuss models. These models use the rule of mixture (blending of individual input components, that is, fiber and matrix). The Voigt model is characterized by isotropic strain, being very well usable for determining the elastic constants $E_{11}, v_{12}$ defined by expressions (2) and (3). The Reuss model is usable for determination of the constants $E_{22}, G_{12}$ defined by expressions (4) and (5) and unlike the Voigt model, it is characterized by isotropic tension.

$$
\begin{aligned}
\frac{d \sigma_{11}}{d \varepsilon_{11}} & =V^{f} \frac{d \sigma^{f}}{d \varepsilon^{f}}+V^{m} \frac{d \sigma^{m}}{d \varepsilon^{m}} \Longrightarrow \\
E_{11} & =V^{f} E_{11}^{f}+V^{m} E^{m}, \\
v_{12} & =V^{f} v_{12}^{f}+V^{m} \nu^{m}, \\
E_{22} & =\frac{E_{22}^{f} E^{m}}{E^{m} V^{f}+E_{22}^{f} E^{m}}, \\
G_{12} & =\frac{G_{12}^{f} G^{m}}{G^{m} V^{f}+G_{12}^{f} E^{m}},
\end{aligned}
$$

where $E_{11}^{f}, E_{22}^{f}$ are the longitudinal and transverse modulus of the elasticity of the fibers, $G_{12}^{f}$ is the shear modulus of the fibers, and $v_{12}^{f}$ is the Poisson number in the plane of the principal direction of the fiber load.

The semiempirical, homogenized and elastic-elastic models were created later than phenomenological models, and based on the new information and knowledge they are still being modified. Their development led in particular to the further expansion of the Voigt and Reuss models, generally modifying these models onto some correction factors that refine the resulting elastic constants for the given types of input components. This category includes models that are implemented in certain modifications into numerical programs using finite element methods such as the Chamis model. The Chamis model in order to calculate the other elastic constants introduces a root square of the fiber volume ratio
TABLE 1: Mechanical properties of the UD prepreg material (with reference to fiber direction).

\begin{tabular}{cccccc}
\hline$E 1[\mathrm{MPa}]$ & $E 2[\mathrm{MPa}]$ & $\rho\left[\mathrm{g} / \mathrm{cm}^{3}\right]$ & $\mu[-]$ & Ductility [\%] \\
\hline Carbon & 101,000 & 9,000 & 1,8 & 0,25 & $\lim \rightarrow 0$ \\
\hline
\end{tabular}

$\sqrt{V^{f}}$, which, in accordance with the weight conservation law, has in (6) the character of the fiber incompressibility.

$$
G_{23}=\frac{G^{m}}{1-\sqrt{V^{f}}\left(1-G^{m} / G_{23}^{f}\right)}
$$

where $G_{23}^{f}$ is the shear modulus of the fiber elasticity in a plane perpendicular to the main direction of loading.

From the elastic model, based on the volume module obtained from the longitudinal strain, it is possible to get the Poisson number expressed by the following relation:

$$
v_{23}=\frac{K-c^{*} G_{23}}{K+c^{*} G_{23}}
$$

where $c^{*}=1+4 K\left(v_{12}^{2} / E_{11}\right)$ and $K$ is a volume module obtained from a longitudinal strain expressed as

$$
K=\frac{K^{m}\left(K^{f}+G^{m}\right) V^{m}+K^{f}\left(K^{m}+G^{m}\right) V^{f}}{\left(K^{f}+G^{m}\right) V^{m}+\left(K^{m}+G^{m}\right) V^{f}} .
$$

2.3. FEM Model. The fundamental phase for solving vibrational transmission of mechanical systems is to propose an appropriate analytical and numerical model. The model should consist of individual discrete elements, model that describes the body as a continuum, or a numerical model based on the FEM method. Computer simulations which use explicit/implicit algorithm can be used to significantly improve the description of nonlinear viscoelastic and viscoplastic behavior for a permanently deformed structure such as fiber composites. The behavior of mechanical system is usually described by the motion equations. The number of equations corresponds to the degrees of freedom in the solved system. The parameters of the individual discrete elements create computational model. By solving the equations, we obtain the dependence of position, velocity, and acceleration in time. The overall requirements on the complexity of the model increase with an arising frequency of excitation and proportionally increase also the number of considered discrete elements and complexity of the model. Quite interesting historical research in this field was conducted by Cawley [37] who compared meshes $6 \times 6$ and $5 \times 5$. The obtained results showed differences in natural frequencies less than $2 \%$. The created model has been carried out in the composite preprocessor of ANSYS software as a layered shell part (Figure 2). The material model of UD prepreg plies could be seen in Table 1. For the standard model, the interlayers between the individual plies were considered as an ideal; it means being considered with the standard mechanical parameters of the used matrix. Here, we used the empirical equation of the deformation properties of the composite materials and the verification of its relationship with the 

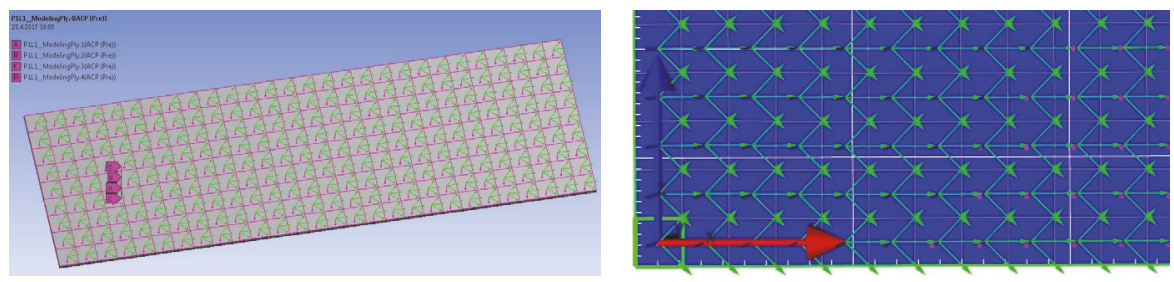

FIGURE 2: The created mapped mesh and directional vectors in ACP.

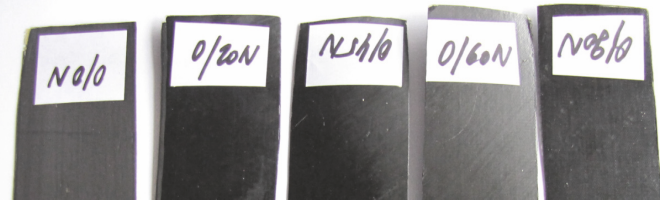

FIGURE 3: Composite samples from UD carbon prepreg.

simulation model. In the case of the additional layers like the inner and outer neoprene ply and the rubber coating, the interface between composite and these materials was modeled as contact deboning with the defined maximum normal traction of $30 \mathrm{MPa}$ and value of normal and shear separation of $0.05 \mathrm{~mm}$. The mesh statistics for the model solved as a shell contain 900 nodes and 560 hexa elements. The composite plate was fixed from one side like in the real case. In the case of vibrational response, the excitation force was applied at the free end.

2.4. Used Material Samples. The tested samples of size 120 $\times 40 \mathrm{~mm}$ were arranged with chosen plies orientation that should cover the standard values used for functional parts. The stacking sequence was created in order to minimize the absolute value in the change of angles, which in case of inappropriate design could increase stress at the interface of the layers. So parts with layouts $0 / 0 / 0 / 0,0 / 20 / 0 /-20$, $0 / 45 / 0 /-45,0 / 60 / 0 /-65$, and $0 / 90 / 0 /-90$ have been produced from wide sheets and subsequently cured under the pressure and temperature of $150^{\circ} \mathrm{C}$ for 15 minutes. In Figure 3, it could be seen that, in this way, prepared composite samples consist of four layers of preimpregnated UD carbon. Prepreg was produced from reinforcement of high strength carbon fibers with unidirectional orientation (nominal area weight $150 \mathrm{~g} / \mathrm{cm}^{2}$, nominal fiber density $180 \mathrm{~g} / \mathrm{m}^{3}$ ) and epoxy resin. Nominal resin content was $38 \%$, nominal area weight $242 \mathrm{~g} / \mathrm{m}^{2}$, and cure cycle $60 \mathrm{~min}$ at $120^{\circ} \mathrm{C}$. In Figure 4 there are pictures from scanning electron microscopy (SEM). The thickness of individual layers after their finishing was $0.16,0.29,0.4$, and $0.52 \mathrm{~mm}$. According to conducted measurements and to [38], the final thickness after polymerization is approximately $85 \%$ of the original one $(0.2 \mathrm{~mm})$. In fiber-reinforced composites we need to distinguish between viscoelastic properties of the matrix and the fibers and interphase which is the region adjacent to the fiber length. Because of those viscous properties the composite materials have time-dependent behavior.

Other samples supplemented by the inner and outer neoprene damping layers were produced according to the original samples. A rubber cover at the top layer was used as a second possibility of the added damping element.

\section{Samples Weight}

(i) Pure composite: 5,34 $\pm 0,15 \mathrm{~g}$

(ii) With inner damping: $6 \mathrm{~g}$

(iii) With outer damping: 6,34 g (the same value of fiber + acryl layer)

(iv) Rubber damping layers: 6,8 g.

Considerable amount of research works has been done on damping analysis of fiber-reinforced composites $[2,5,23$, 33 , 37]. The main damping principles can be distinguish according to the following groups:

(i) Energy dissipation arising due to the high shear strain in the interphase region

(ii) Damping due to damage

(iii) Frictional damping in the unbounded regions.

(iv) Damping of energy dissipation in the area of matrix cracks.

(v) Viscoplastic damping: a correlation between the plastic deformation and the increase of damping at high stresses

(vi) Thermoelastic damping: it describes the coupling between the elastic deformation in the matrix and an arising temperature field.

Another significant possibility is inclusion of an additional viscoelastic damping layer. In one case, the viscoelastic layers were composed of the base neoprene fiber layer covered by a rigid layer of acrylate. In the second case, the neoprene layer was inside the interphase of inner plies in the created part as could be seen in Figure 5 or as described in $[6,9]$.

Another possibility to improve or specifically affect the damping of fiber-reinforced material is with using rubber layer. In the work of [39] we could read about reinforcing rubbers with long or short fibers to form composites and their behavior in dependency on temperature. Advantages of this so-called advanced hybrid structures based on steel, rubber, and FRP were described by Sarlin et al. in their work [40]. They mentioned that, with a good combination of constituent materials and the interfacial properties, it is possible to achieve surprising mechanical and also dynamic properties with low weight. In our case on the top of the composite material also the coat consisting of three rubber 

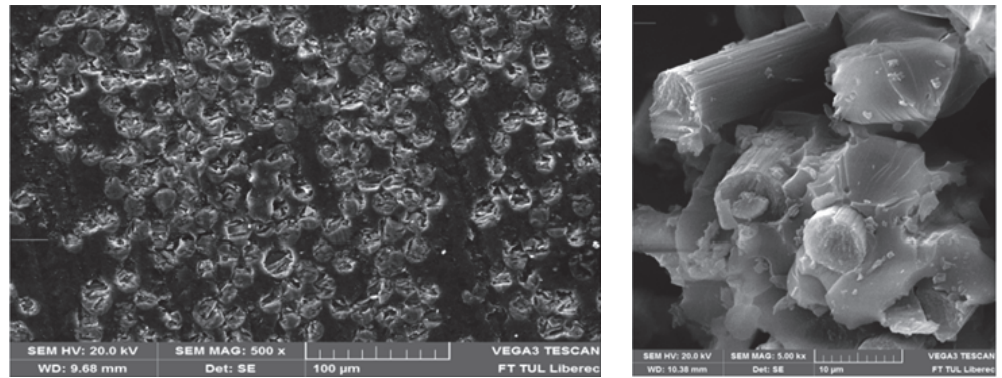

FIGURE 4: Examples of the inner structure of the created composite samples from UD carbon prepreg.

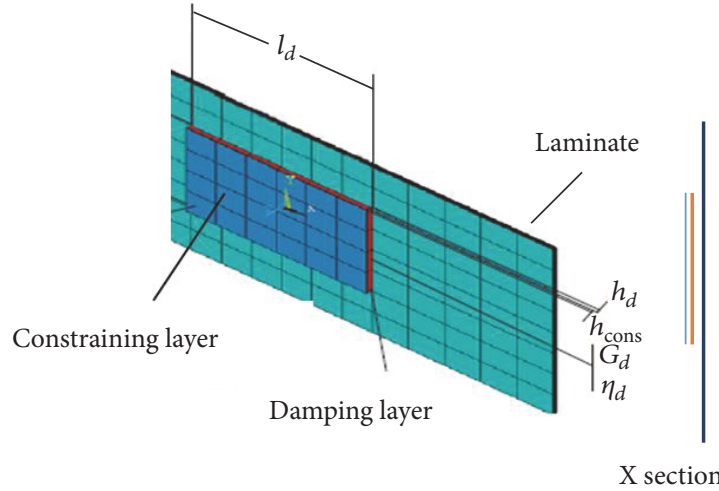

(a)

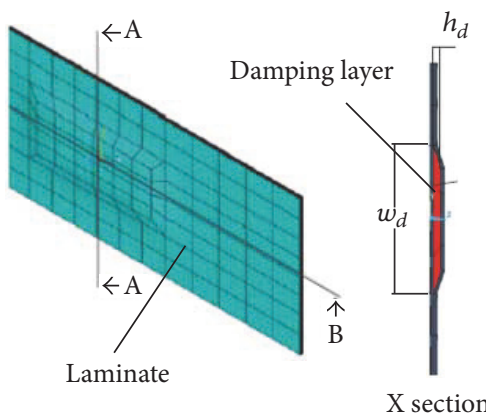

(b)

FIGURE 5: Possibilities of implementation of damping element: (a) constrained layer damping treatment; (b) integrated layer damping treatment (edited according to [6]).

plies was created. It was not necessary to use glue or any special treatment, just to clean and degrease the top ply, and subsequently the hot rubber material was sprayed. An example of the pure layer and material covered with one rubber film could be seen in Figure 6(a). In Figure 6(b) and Figure 7, the next described variants with inner and outer viscoelastic layers are shown.

Finally, the samples from standard low carbon steel (S235JRG1) with the same size as the composite samples, 120 $\times 40 \mathrm{~mm}$, and thickness of $1 \mathrm{~mm}$ have been prepared and experimentally tested for their transmission characteristics in order to illustratively compare their properties with the laminates.

\section{Testing of Vibration Response}

Two basic methods when the composite body is from one side vibrationally excited and on the other scanned could be used to locate the transmission characteristics by experiment. The first way is to make one-sided clamping jaws excited by a controlled signal. In terms of excitation, hydraulic system is better utilized. Its advantages are the fluent speed regulation and shock absorption, that is, motion without "jumps" that are typical for pneumatic systems caused by the compressibility of the inner medium. The second option is to use so-called modal hammer that excites broad spectrum by a short impulse [1]. The subsequent response is monitored and evaluated. These methods can be further divided according to the dynamic responses to modal analysis, frequency domain, time domain, and the impedance domain. Excitation and response are processed by the signal analyzer [5]. Damping characteristics of the beam are derived from the response of the input signal using the Fourier transform. Also some nondestructive evaluation (NDE) techniques such as acoustic emission and vibration damping techniques could be also applied to characterize the fiber-reinforced composites $[1,8$, $13,37]$. The damping capacity of a material is the fundamental property for designing and manufacturing structural components in dynamic applications. Materials with high damping capabilities are very desirable to suppress mechanical vibration and transmission of waves, thus decreasing noise and maintaining the stability of structural systems. Experimental and analytical characterization of damping is not easy, even with conventional structural materials, and the anisotropic nature of composite materials makes it even more difficult. Theories of Lagrange, Euler-Bernoulli, Rayleigh, and Timoshenko [11, 36, 41, 42] based on a vibration of thin beams are in this area mostly used. Modal vibration tests are usually based on the measurement of modal frequencies, damping factors, and the mode shapes on the specimens or parts. They have potential quickly and precisely provide enough basis of rapid and inexpensive characterization of elastic and viscoelastic properties of the tested materials. Generally, the damping in metal structures is low, which results in high amplitudes of the vibrations. The damping of the fiber-reinforced composite materials is generally higher 


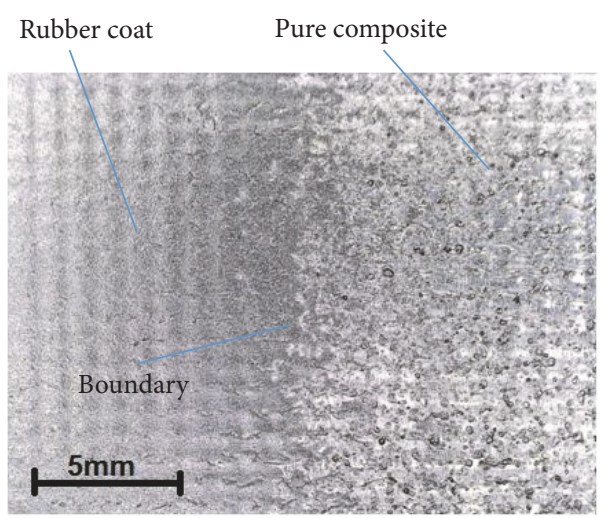

(a)

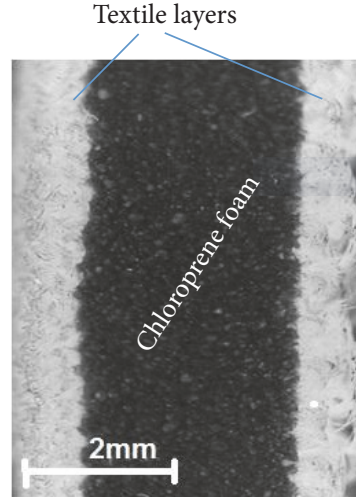

(b)

FIGURE 6: Created samples: (a) the top surface and transition between the pure and rubber coat surface; (b) structure of the viscoelastic neoprene material.

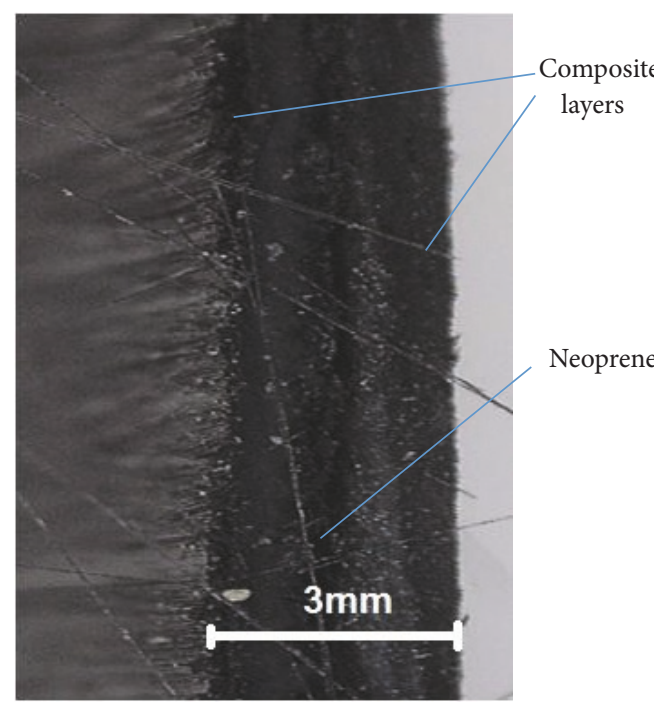

(a)

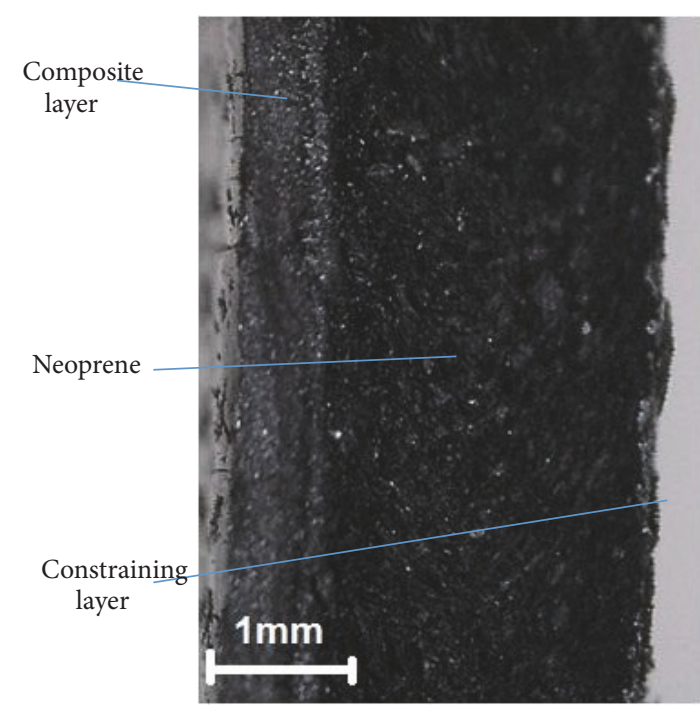

(b)

FIGURE 7: Cross section of the tested samples with the additional (a) inner and (b) outer neoprene layers.

and significantly depends on the constitution of materials. For a cantilever beam subjected to free vibration, the system is considered as continuous system in which the beam mass is considered as distributed along with the stiffness of the shaft; the equation of motion can be written as follows [43]:

$$
\frac{d^{2}}{d x^{2}}\left[E I_{(x)} \frac{d^{2} Y_{(x)}}{d x^{2}}\right]=\omega^{2} m_{(x)} Y_{(x)}
$$

where $E$ is the modulus of rigidity of beam material, $I$ is the moment of inertia of the beam cross section, $Y_{(x)}$ is displacement in $y$ direction at distance $x$ from fixed end, $\omega$ is the circular natural frequency, $m$ is the mass per unit length, $m=\rho A(x), \rho$ is the material density, and $x$ is the distance measured from the fixed end.
For our case of cantilever beam, the integral constant is based on known boundary conditions at the free and clamped point of the flat beam (see (10) and (11)):

At

$$
\begin{aligned}
x & =0, \\
Y_{(x)} & =0, \\
\frac{d Y_{(x)}}{d x} & =0
\end{aligned}
$$

At

$$
\begin{aligned}
x & =0, \\
\frac{d^{2} Y_{(x)}}{d x^{2}} & =0, \\
\frac{d^{3} Y_{(x)}}{d x^{3}} & =0 .
\end{aligned}
$$


Berhelot and Summerscales [5, 44] applied the Ritz Method to perform the damping calculations and experiments of various composites, including unidirectional glass/Kevlar fibers composites with some interleaved viscoelastic layers, and further completed the damping analysis of composite plate and structures by using this method. On the basis of transfer functions, the modulus of elasticity and size of the Poisson's constant can be determined. Material damping is commonly modeled for technical purposes, using the socalled "relaxation model." This is a parallel connection of a spring with stiffness $\left(k_{1}(\mathrm{~N} / \mathrm{m})\right)$ and a viscous damper $(b=\mathrm{Ns} / \mathrm{m})$ in series connected with spring $k_{2}(\mathrm{~N} / \mathrm{m})$ mathematically described as

$$
\begin{aligned}
& F(t)=w_{o} \frac{1}{k_{2}^{2}+\omega^{2} b^{2}}\left(\left(k_{1} k_{2}^{2}+\omega^{2} b^{2}\left(k_{1}+k_{2}\right)\right) \sin \omega t\right. \\
& \left.\quad+\left(\omega k_{2}^{2} b\right) \cos \omega t\right)
\end{aligned}
$$

wherein the process $F(t)$ precedes the process $w(t)$ by a phase angle $\varphi$, whose tangent $\operatorname{tg} \varphi=\eta$. $\eta(\omega)$ is the loss tangent, usually called the loss factor.

For most of damping materials, there is a dependency of loss tangent $\eta$ on the angular frequency $\mathrm{rad} / \mathrm{s}$ similar to the dependency of the ideal relaxation model. According to [45], an empirical relation (13) for modal frequencies of a flat cantilever beam is

$$
f_{n}=\frac{\left(\lambda_{n} L\right)^{2}}{2 \pi^{2}}\left(\frac{E I}{\rho A}\right)^{2}
$$

where $f_{n}$ is frequency of $n$th mode $(\mathrm{Hz}), E$ is modulus of beam material, $I$ is moment of inertia of beam about its neutral axis, $\rho$ is density of beam material, $A$ is crosssectional area of beam, $\lambda_{n}$ is eigen value for $n$th mode which depends on boundary conditions, and $L$ is the beam length. Laminated composite plates have been analyzed by many authors $[3,4,45]$. It is well documented that shear deformation can have significant influence on the natural frequencies of such plates. The damping property of this kind of plates is usually expressed in terms of the modal loss factor $\eta$ calculated for each vibration mode of the plate. The degree of internal damping (14) is calculated by applying the halfpower bandwidth.

$$
\frac{Q}{\sqrt{2}}=\frac{1}{2 \sqrt{2} \xi},
$$

where $Q$ is called quality factor, equal to $Q=X / \delta_{S T}$ at the time when the frequency ratio $r=\omega / \omega_{n}=1$.

The loss tangent describes properties of materials and their inner attenuation. Sometimes damping properties coordinate by a phase angle $\varphi=\arctan \eta$, which is called the loss angle. The main parameter describing the material damping properties is the coefficient $\xi$ (in literature often referred to as just KSI). Validation was performed on a frequency response using the so-called loss factor. The loss factor is in this case given as $\eta=2 \xi$, where $\xi$ is structural damping of material during resonance. The size of the loss factor

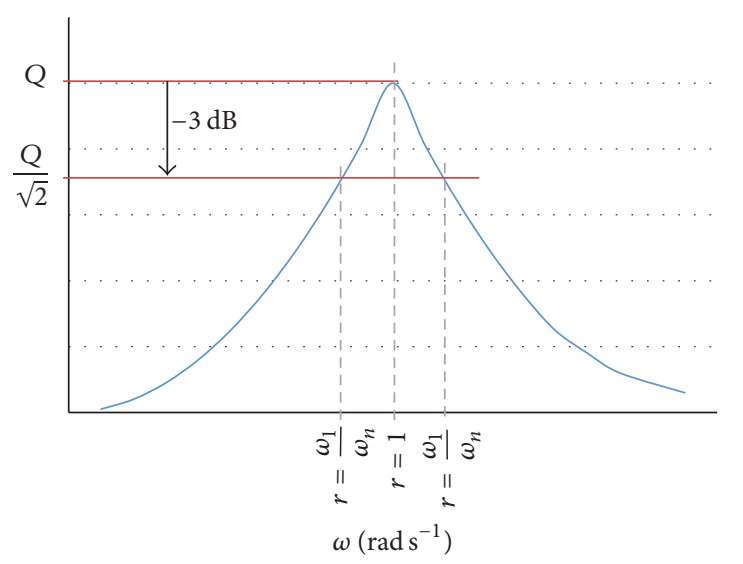

FIGURE 8: The graph of principle of measurement structural damping at resonance.

can be determined in two ways: as dynamic damping or attenuation in dependency on time. Resonance is determined when performance decreased by $3 \mathrm{~dB}$ (15) using the halfpower points $\omega_{1}$ and $\omega_{2}$ as could be seen in Figure 8 .

$$
\xi=\frac{\omega_{2}-\omega_{1}}{2 \omega_{n}} .
$$

\section{Results and Discussion}

The aim of the experiment was to assess dependency of the layered structure composition on the overall response and transfer function. The composite rectangular plate was mounted to a console by inserting them between two clamping jaws (Figure 9(a)) [1]. It was necessary to provide polished clamping surfaces for perfect fixing of the sample and to avoid possible undesirable vibrations. Accelerometer Accl was mounted near to the jaws and at the free end of the composite sheet the second accelerometer Acc2 was mounted. The excitation impulse has been done by a modal hammer. Accelerometer Accl was using wax stuck near the jaws and at the free end of the tube the second accelerometer Acc 2 was stuck. Properties of the used accelerometers are the mass of $1,2 \mathrm{~g}$, maximal sampling frequency of $5000 \mathrm{~Hz}$, and sensitivity of up to $400 \mathrm{~g}$. The acceleration arising at Accl and its response in Acc2 depending on time are for an angle of $20^{\circ}$ and $60^{\circ}$ shown in Figure 9(b). The excitation force and its response were converted to the frequency spectrum and calculated ratio of these two functions is called the transfer function. This function does not depend on the type of excitation. It is possible to be excited harmoniously, randomly, or by an impulse, and the results of one type of excitation may be used for predicting response of the structure at a different type. In our case the method with modal hammer has been used. The created experimental data were measured with the maximal frequency $2000 \mathrm{~Hz}$. According to the ShannonKotelnik theorem and so-called Nyquist condition (16), the computational sampling frequency was $5000 \mathrm{~Hz}$. The desired output is called a transfer function PSD (17). The function 


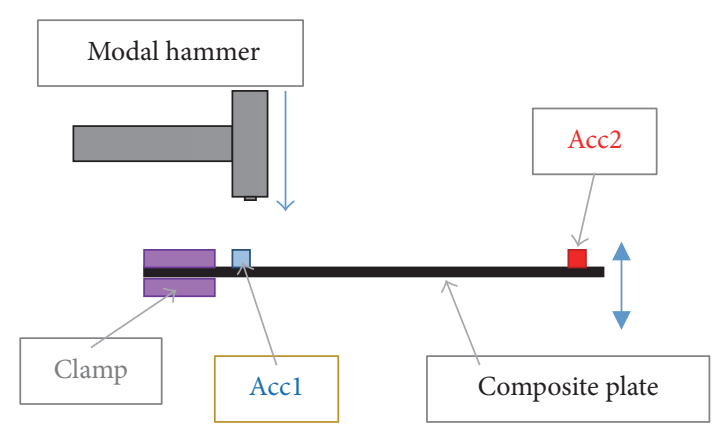

(a)

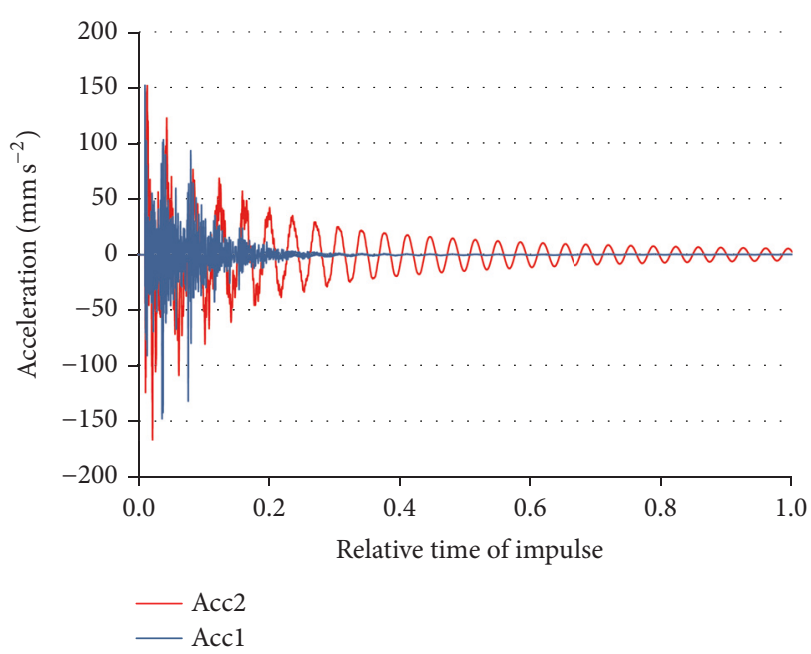

(b)

FIGURE 9: (a) Scheme of the experiment; (b) an example of the measured acceleration.

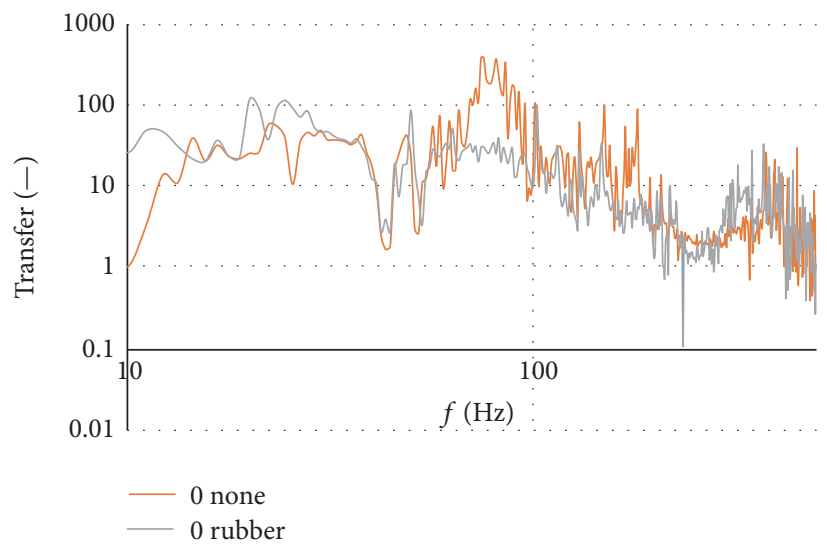

(a)



(b)

FIGURE 10: Examples of the transfer functions for different damping materials with the plies layout 0/0/0/0.

PSD indicates which part of the total transmitted power is carried by a respective frequency.

$$
f_{\text {samp }} \geq 2 f_{\text {max }},
$$

where $f_{\text {samp }}\left[\mathrm{s}^{-1}\right]$ is the sampling frequency and $f_{\max }\left[\mathrm{s}^{-1}\right]$ is the highest frequency contained in the signal.

$$
H(f)=\frac{\text { OUTPUT }}{\text { INPUT }}=\sqrt{\frac{\operatorname{PSD}_{2}(f)}{\operatorname{PSD}_{1}(f)}}=\frac{\operatorname{acc}_{2}(f)}{\operatorname{acc}_{1}(f)} .
$$

The results for the chosen types of the plies orientation in dependency on the used damping material could be seen in Figures 10, 11, 12, 13, and 14. In Figures 15 and 16, results for the samples with inner neoprene damping material in dependency on the plies layout are shown. In the graph in Figure 17(a) there are the sought values of structural damping coefficient for steel and composite material compared in order to show another advantage of using layered materials instead of the conventional materials from the point of view of the resonant damping. As has been already mentioned, the structural damping is probably the most appropriate tool that is possible to use for mutual comparison of two usually hardly comparable materials due to their different stiffness, density, and volume. In Figure 17(b) values of the structural damping for the tested parts with the added viscoelastic layers are shown.

Finite element analysis allows us to derive the different strain energies stored in the material directions in the constituent plies of composite materials [12]. The energy dissipated by damping in the composite structure could be obtained as a function of the strain energies and the damping coefficients associated with the different energies stored in the material directions. It is assumed that the same displacement distribution in the individual layers is capable of representing displacement discontinuity conditions at interfaces between layers. The value of energy dissipated by damping in the composite structure can be obtained as a function of the damping coefficient with respect to the reference angles of individual plies. Simulation of composites uses so-called 


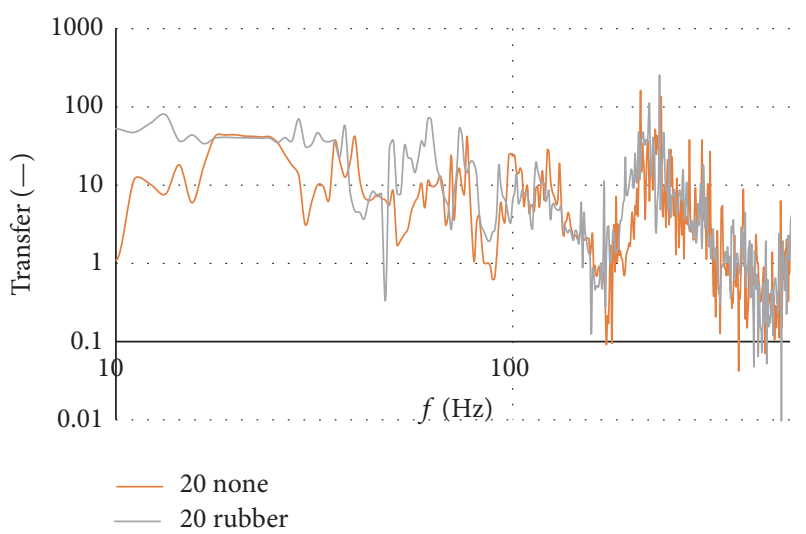

(a)

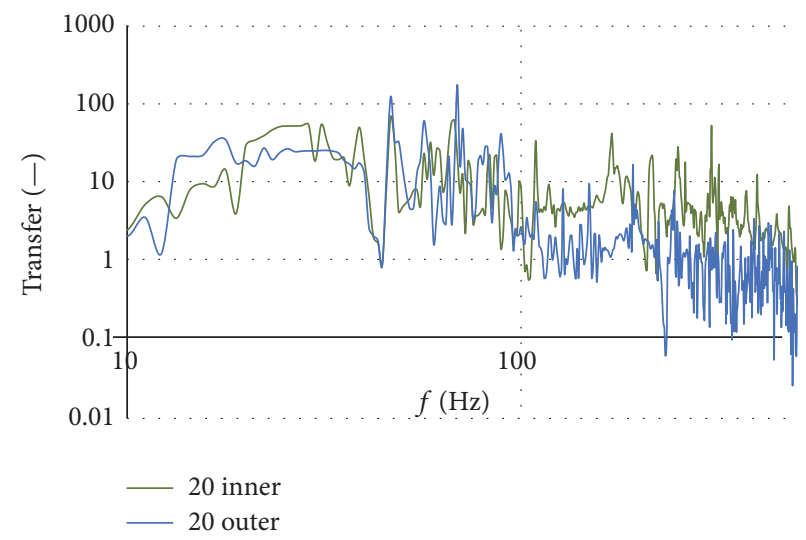

(b)

FIGURE 11: Examples of the transfer functions for different damping materials with the plies layout 0/20/0/-20.

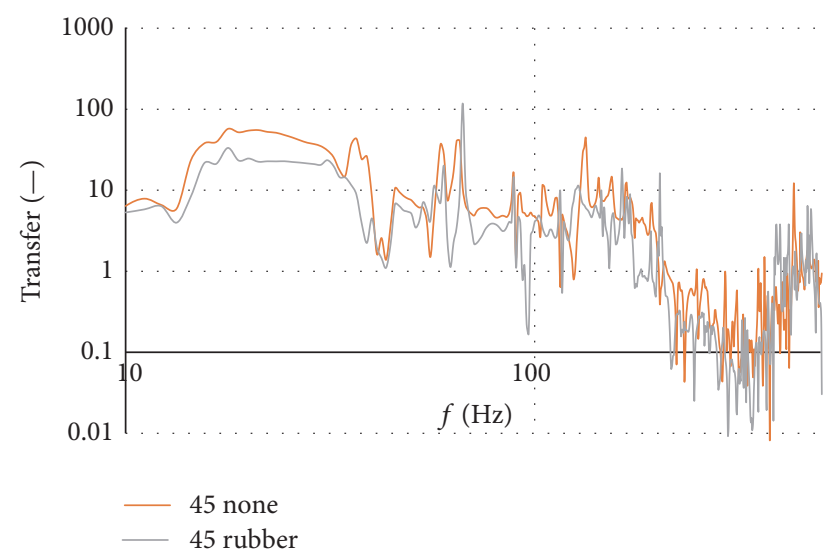

(a)

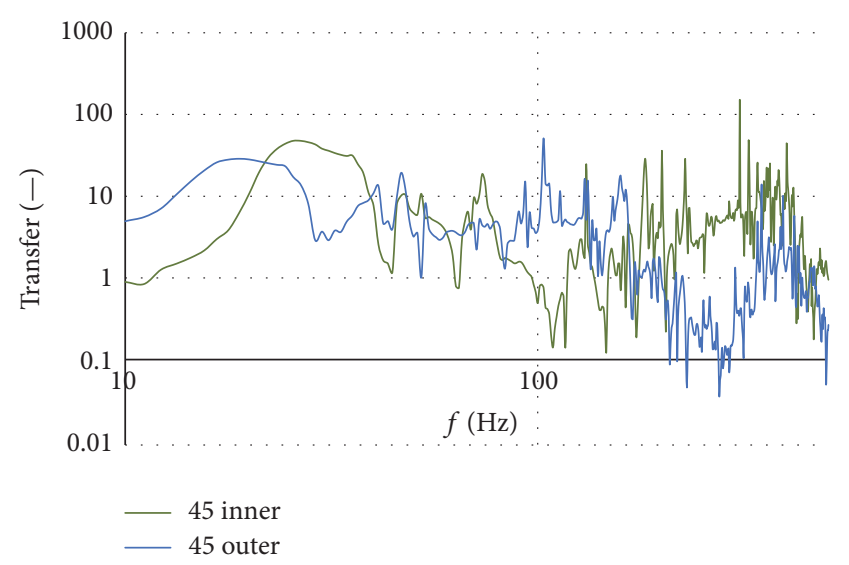

(b)

FIGURE 12: Examples of the transfer functions for different damping materials with the plies layout 0/45/0/-45.

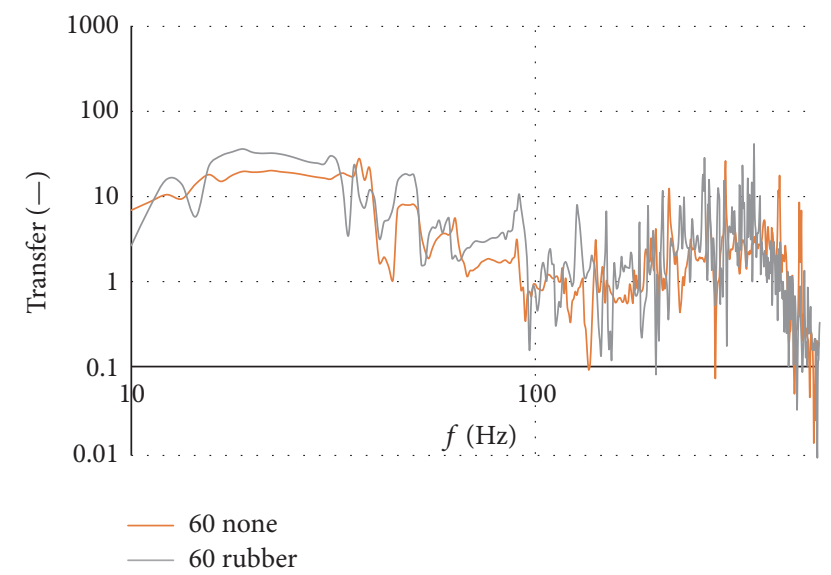

(a)

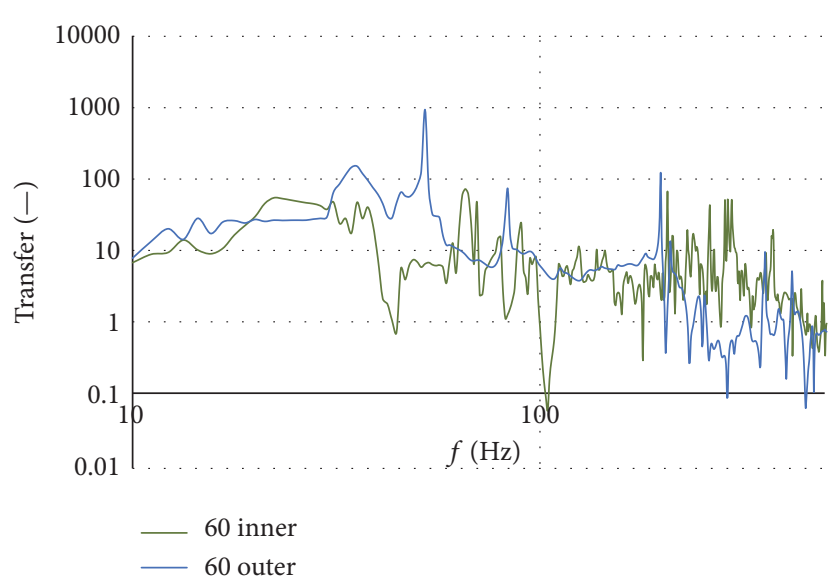

(b)

Figure 13: Examples of the transfer functions for different damping materials with the plies layout 0/60/0/-60. 


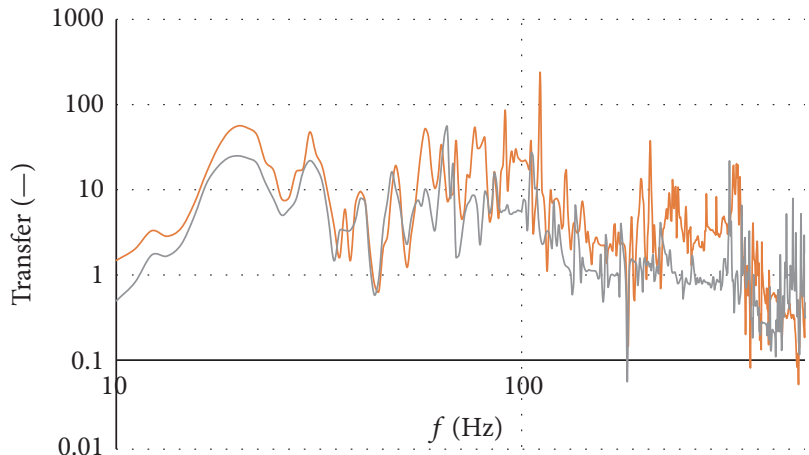

-90 none
-90 rubber

(a)

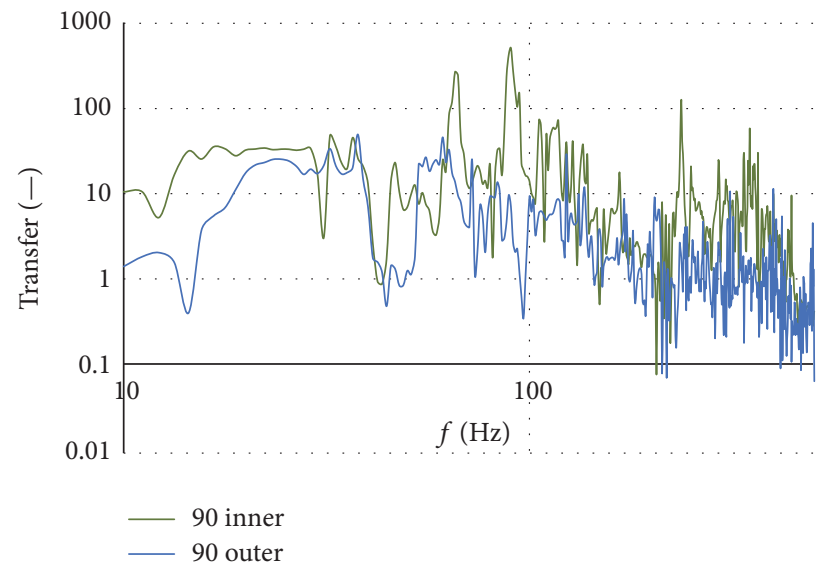

(b)

FIGURE 14: Examples of the transfer functions for different damping materials with the plies layout 0/90/0/-90.



(a)

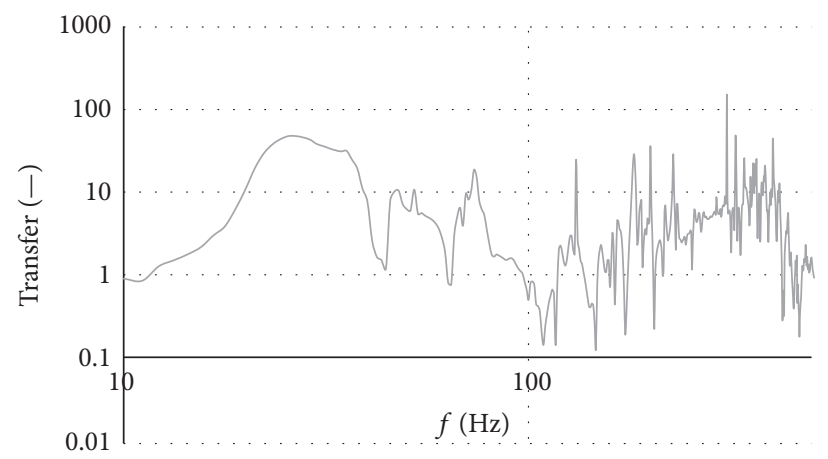

45 inner

(b)

FIGURE 15: Transfer functions of composites $0 / 0 / 0 / 0$ and $0 / 45 / 0 /-45$, with the inner additional damping materials.

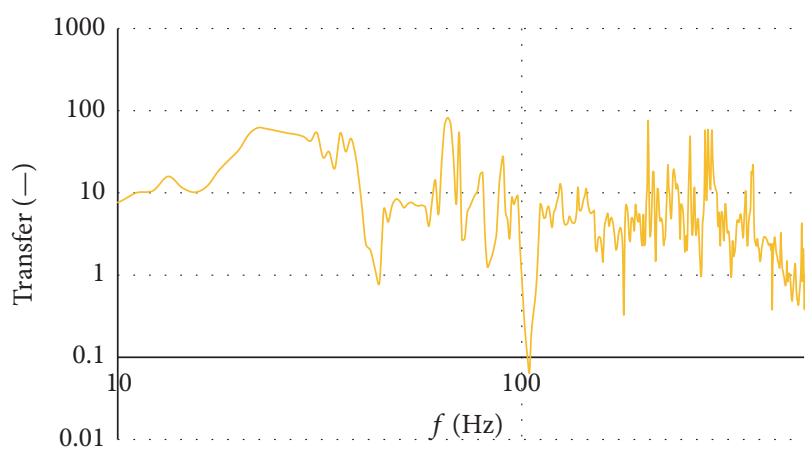

60 inner

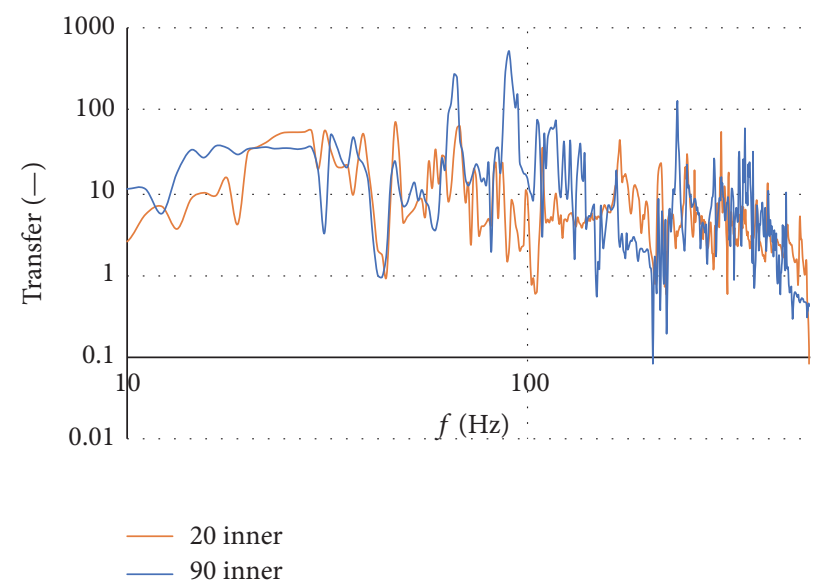

(b)

FIGURE 16: Transfer functions of composites $0 / 60 / 0 /-60,0 / 20 / 0 /-20$, and 0/90/0/-90, with the inner additional damping materials. 
Structural damping $\xi$



(a)



(b)

FIGURE 17: Comparison of the structural damping characteristics between (a) steel and composite parts and (b) individual composites with the additional layers.



FIGURE 18: Example of modifying shape of the fourth mode by changing direction of two from 4 layers.

layer-wise theory. We suppose that based on the distribution of displacement among the individual layers it is possible to predict some discontinuous conditions at the layer interface $[3,4]$. Damping measurement in composite materials uses combined finite element and frequency response method [10]. Based on the CAD geometry and measured material characteristics [1] with using the ACP preprocessor a FEM model of layered shell parts (Figure 2) has been built. The simulation itself was distributed into 2 parts: modal analysis and frequency response [12]. The material model was defined as a shell and presented by the necessary tensile and shear modulus of elasticity for each direction, density, and Poisson's ratio. On the chosen resulting visualizations (Figure 18), it is possible to quite clearly see the individual natural frequencies and examples of their swapping from bending to torsion simultaneously with changing the fibers direction. If increase of the natural frequencies of some mode is required, the fiber orientation of each layer of the laminates or one of the size parameters of the plates should be tailored. The resulting transfer characteristics for various angles of individual plies direction solved in ACP ANSYS can be seen in Figures 19 and 20. The results are in two separated graphs because the $0 / 0 / 0 / 0$ layout has diametrically lower values of the found transfer characteristics. 
TABLE 2: Overview of the found natural frequencies $[\mathrm{Hz}]$.

\begin{tabular}{|c|c|c|c|c|c|c|c|c|c|c|c|}
\hline Model & 35 & 143 & 222 & 640 & 1061 & 1314 & 1536 & 1925 & 2295 & 2295 & 2988 \\
\hline Experiment & 29 & 144 & 173 & 648 & 1012 & 1237 & 1429 & 1894 & 2241 & 2241 & 3107 \\
\hline Deviation & $17 \%$ & $-1 \%$ & $22 \%$ & $-1 \%$ & $5 \%$ & $6 \%$ & $7 \%$ & $2 \%$ & $2 \%$ & $2 \%$ & $-4 \%$ \\
\hline
\end{tabular}

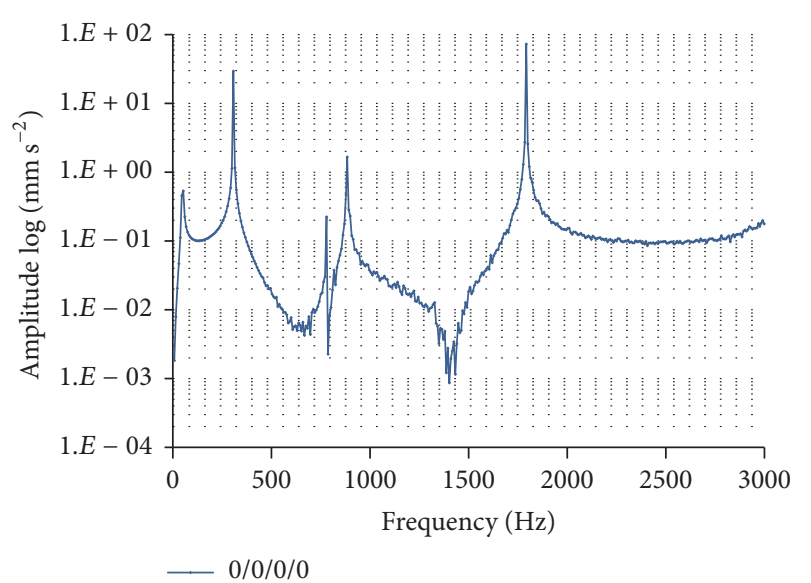

FIgURE 19: Result of the numerical model, transfer function for 0/0/0/0 oriented plies.

All of the found results for continuous carbon fiberreinforced composites show that when strain levels are low the damping characteristics do not depend on strain amplitude but do depend on the fiber orientation. Generally it is necessary to consider also temperature, moisture absorption, frequency, and matrix properties. The main fiber properties have only minimal effects. However, for discontinuous fiberreinforced composites it has been shown that the damping characteristics in the fiber direction are much higher than any other directions. It is commonly accepted that the main sources of damping in a composite material come from microplastic or viscoelastic phenomenon associated with the matrix and slippage at the interface between the matrix and the reinforcement of the individual plies. The experiment is a quick way to find out the basic modal and transmission characteristics. Then, primarily based on the practical knowledge, it is possible to determine which modes are significant and which are just some noise or, for example, sidebands. The numerical model could give us clear overview of the modes shape; however, their real size and relevance are necessarily verified by experiment. Usually in the model we could find more modes, and then based on the experiment it is possible to identify their relevance. As is shown in Table 2 for the selected case of ply orientation, $0 / 45 / 0 /-45^{\circ}$ are the numerically and experimentally found natural values which are quite similar. Significant differences are primarily at low frequencies and perhaps there is a place where all the imperfections of manufacturing process, mass of the accelerometers, and idealization in the material model will be reflected. Use of an additional damping tool like the tested inner and outer viscoelastic layers or the rubber cover of the material can make the entire damping increase with an almost negligible effect.



FIGURE 20: Results of the numerical model, transfer function for 4 different oriented layers.

\section{Conclusion}

In this presented work the experimental and numerical determination of the own frequencies and transient response for prepreg plates consisting of 4 layers have been carried out. Two layers (1st and 3rd from the top) were oriented still in the longitudinal direction; for the 2nd one the angle was variable in the range of $0,20,45,60$, and $90^{\circ}$ and the remaining 4 th one was the inverse to the 2 nd (it means 90 , $-20,-45,-60$, and $0^{\circ}$ ). The expected strong dependency of the transition function (its shape at some particle modes including their size) on the individual plies orientation has been found. On the basis of the experimentally obtained material data $[25,26]$, the numerical model has been compiled. Using this model was possible to thoroughly track the process and explore changes in the shape of individual modes and the response of the whole structure. Results of the numerical simulations and experiment were in good agreement. Generally we could say the following: (1) For composite parts, the error resulting from the simulation every time will be bigger than for isotropic materials (e.g., steel parts). This is caused by many parameters and conditions that we have to consider during the part creation (grease, pressure, temperature, imperfect vacuum, and real thickness of plies) and this fact, whether we like it or not, will almost always significantly affect the final mechanical parameters. When creating the numerical model, the results precision depends also on the chosen approach, whether we could compute just the shell model or create solid parts that could be enhanced with the real arising interlaminar defects, error criteria, and so on. (2) The expected advantages of using some additional damping presented by the viscoelastic components have not proved to be significant. Especially at the lower 
frequencies, it is possible to find even some decrease of the inner structural damping. This could be quite important for real manufactured parts because they are almost often covered with some gel coat, acryl, or PUR paint, and so on and the standard simulations do not take into account also those factors. Even if the use of the additional viscoelastic layers is measurable, due to significant rise of the cost, increasing of manufacturing time and necessary higher complexity of the used technologies are not possible to be recommended. (3) By changing the orientation of the fibers we can shift the individual peaks and modify the transmission. It is even possible to change the character of own frequencies, for example, in Figure 18, where it is possible to find changes from bending to torsion. The presented results are important particularly for the possibility of finding the response of the whole structure depending on the changes in the angle of individual layers. This could help us in our concepts to shift the modes or avoid developed devices to operate in the critical frequency areas. The results of presented work are important especially for the idea of how changing the inner structure of composite material, eventually adding some cover layers, could influence and change the main characteristic like the resonant frequency and their shape. The found results correspond with conclusions of many authors. The only ones who have achieved quite different results are Kishi et al. [8], in which case the value of structural damping still increased even with the increasing frequency. Such possibility has not been proven in any of carried models or experiments or any of found publication for either the composite structure or the composite with the additional viscoelastic layers. Our results agree with [6], who mentioned high importance of precise measurement of the material properties also in various temperature dependent behaviors and significant dependency on the manufacturing conditions, that in the prototype laboratory conditions means a very poor repeatability. In his work he also declared that there could be some benefits in using the inner viscoelastic layer. It could be true for the mechanical parameters like stiffness and buckling properties, but in our work any measurable improvement of the damping properties has not been found. Whitney [46] was from today's perspective historically devoted to the distribution of stress in individual composite layers. Nowadays great tool from this point of view is the numerical simulation, where we could describe the resulting stress and strain for the whole material and also each of the individual layers. It is possible to agree with [10] who mentioned that based on the KSI and transfer function the important mechanical parameters that characterize composite materials could be obtained with a high level of accuracy. Our results also correspond with the found high level of the structural damping (compared with steel materials), especially at the lower frequencies. As mentioned in [14], when comparing experiment and model of composite parts, seemingly high differences usually arose, but in fact the model-based trends (mode shape, delamination, ruptures, etc.) are usually accurate and differ only in their precise numerical values. The significant dependence on the orientation and composition of the layers, mentioned by $[7,15]$, has been obtained and proved. Their changing could not only shift the individual modes and their frequencies, but also change their shapes and significantly affect the inner structural damping.

\section{Conflicts of Interest}

The authors declare that they have no conflicts of interest.

\section{Acknowledgments}

The results of this project, LO1201, were obtained by cofunding from the Ministry of Education, Youth and Sports as part of targeted support from the "Národní program udržitelnosti I" programme.

\section{References}

[1] P. Kulhavy, J. Petrik, P. Srb, and P. Lepsik, "Vibration response of composite structures," in Proceedings of the 54th International conference on Experimental Stress Analysis, University of West Bohemia, 2016.

[2] L. Kherredine, S. Gouasmi, R. Laissaoui, and N. E. Zeghib, "Evaluation and measurement of the damping properties of laminated CFRP composite plates," in Proceedings of the National Conference on Materials, MATERIAUX 2010, November 2010.

[3] W. Wang and T. Kam, "Material characterization of laminated composite plates via static testing," Composite Structures, vol. 50, no. 4, pp. 347-352, 2000.

[4] G. A. Lesieutre, "Modeling frequency-dependent longitudinal dynamic behavior of linear viscoelastic long fiber composites," Journal of Composite Materials, vol. 28, no. 18, pp. 1770-1782, 1994.

[5] J.-M. Berthelot, M. Assarar, Y. Sefrani, and A. E. Mahi, "Damping analysis of composite materials and structures," Composite Structures, vol. 85, no. 3, pp. 189-204, 2008.

[6] G. Lepoittevin, Composite Laminates with Integrated Vibration Damping Treatments, Dissertation thesis [Ph.D. thesis], ETH Zurich, 2012.

[7] K. Sepahvand, "Stochastic finite element method for random harmonic analysis of composite plates with uncertain modal damping parameters," Journal of Sound and Vibration, vol. 400, pp. 1-12, 2017.

[8] H. Kishi, M. Kuwata, S. Matsuda, T. Asami, and A. Murakami, "Damping properties of thermoplastic-elastomer interleaved carbon fiber-reinforced epoxy composites," Composites Science and Technology, vol. 64, no. 16, pp. 2517-2523, 2004.

[9] P. Cupiał and J. Nizioł, "Vibration and damping analysis of a three-layered composite plate with a viscoelastic mid-layer," Journal of Sound and Vibration, vol. 183, no. 1, pp. 99-114, 1995.

[10] B. S. Bena, B. A. Benb, K. C. Adarsh, K. A. Vikram, and Ch. Ratnamd, "Damping measurement in composite materials using combined finite element and frequency response method," International Journal of Engineering Science Invention, 2010, Proceedings of the Advances in Modelling and Analysis of Aerodynamic Systems, vol. 2, National Institute of Technology Rourkela.

[11] C. Kyriazoglou and F. J. Guild, "Finite element prediction of damping of composite GFRP and CFRP laminates - a hybrid formulation - vibration damping experiments and Rayleigh damping," Composites Science and Technology, vol. 67, no. 11-12, pp. 2643-2654, 2007. 
[12] Y. Zou, L. Tong, and G. P. Steven, "Vibration-based modeldependent damage (delamination) identification and health monitoring for composite structures-a review," Journal of Sound and Vibration, vol. 230, no. 2, pp. 357-378, 2000.

[13] D. A. Saravanos, "Integrated damping mechanics for thick composite laminates and plates," Journal of Applied Mechanics, Transactions ASME, vol. 61, no. 2, pp. 375-393, 1994.

[14] J. H. Yim and J. Gillespie, "Damping characteristics of $0 \circ$ and $90 \circ$ AS4/3501-6 unidirectional laminates including the transverse shear effect," Composite Structures, vol. 50, no. 3, pp. 217-225, 2000.

[15] T. S. Plagianakos and D. A. Saravanos, "High-order layerwise mechanics and finite element for the damped dynamic characteristics of sandwich composite beams," International Journal of Solids and Structures, vol. 41, no. 24-25, pp. 6853-6871, 2004.

[16] D. G. Lee and J. B. Kosmatka, "Damping analysis of composite plates with zig-zag triangular element," AIAA Journal, vol. 40, no. 6, pp. 1211-1219, 2002.

[17] V. Birman and L. W. Byrd, "Analytical evaluation of damping in composite and sandwich structures," AIAA Journal, vol. 40, no. 8, pp. 1638-1643, 2002.

[18] T. Pritz, "Frequency power law of material damping," Applied Acoustics, vol. 65, no. 11, pp. 1027-1036, 2004.

[19] J. P. Talbot and J. Woodhouse, "The vibration damping of laminated plates," Composites Part A: Applied Science and Manufacturing, vol. 28, no. 12, pp. 1007-1012, 1997.

[20] T. Canor, N. Blaise, and V. Denoël, "Efficient uncoupled stochastic analysis with non-proportional damping," Journal of Sound and Vibration, vol. 331, no. 24, pp. 5283-5291, 2012.

[21] M. Morzfeld, N. Ajavakom, and F. Ma, "Diagonal dominance of damping and the decoupling approximation in linear vibratory systems," Journal of Sound and Vibration, vol. 320, no. 1-2, pp. 406-420, 2009.

[22] E. C. Botelho, A. N. Campos, E. De Barros, L. C. Pardini, and M. C. Rezende, "Damping behavior of continuous fiber/metal composite materials by the free vibration method," Composites Part B: Engineering, vol. 37, no. 2-3, pp. 255-263, 2005.

[23] H. Guan and R. F. Gibson, "Micromechanical models for damping in woven fabric-reinforced polymer matrix composites," Journal of Composite Materials, vol. 35, no. 16, pp. 1417-1434, 2001.

[24] Z. Bittnar and J. Sejnoha, Numerical Methods in Structural Mechanics, Pitman Monographs and Surveys in Pure and Applied Mathematics, Applied Mathematics, Thomas Telford Publications, London, UK, 1996.

[25] M. Syrovatkova and M. Petru, "Experimental and numerical analysis of impact test of carbon prepreg composite," in Proceedings of the 54th International Conference on Experimental Stress Analysis, (EAN '16), June 2016.

[26] M. Petru, T. Martinec, and J. Mlynek, "Numerical model description of fibres winding process for new technology of winding fibres on the frames," Manufacturing Technology, vol. 16, no. 4, pp. 778-785, 2016.

[27] W. Voigt, "Uber die Beziehungzwischen den bei den Elastizitatskonstanten Isotroper Korper," Wiedemanns Annalen der Physik und Chemie, Lepzig, vol. 38, pp. 573-587, 1889.

[28] A. Reuss, "Berechnung der Fliessrense von mischkristallen auf grund der plastizitätsbedingung für einkristalle," Zeitschrift für Angewandte Mathematik und Mechanik, vol. 9, no. 1, pp. 49-58, 1929.
[29] R. Younes, A. Hallal, F. Fardoun, and F. H. Chehade, "Comparative review study on elastic properties modeling for unidirectional composite materials," in Composites and Their Properties, chapter 17, 2012.

[30] J. C. Halpin and J. L. Kardos, "The Halpin-Tsai equations: a review," Polymer Engineering and Science, vol. 16, no. 5, pp. 344352, 1976.

[31] C. C. Chamis, "Mechanics of composite materials: past, present, and future," Journal of Composites Technology and Research, vol. 11, no. 1, pp. 3-14, 1989.

[32] T. Mori and K. Tanaka, "Average stress in matrix and average elastic energy of materials with misfitting inclusions," Acta Metallurgica, vol. 21, no. 5, pp. 571-574, 1973.

[33] R. Hill, "Theory of mechanical properties of fibre-strengthened materials-III. self-consistent model," Journal of the Mechanics and Physics of Solids, vol. 13, no. 4, pp. 189-198, 1965.

[34] Z. Huang, "Simulation of the mechanical properties of fibrous composites by the bridging micromechanics model," Composites A: Applied Science and Manufacturing, vol. 32, no. 2, pp. 143$172,2001$.

[35] Z. Hashin and B. W. Rosen, "The elastic moduli of fiberreinforced materials," Journal of Applied Mechanics, vol. 31, no. 2, pp. 223-232, 1964.

[36] R. M. Christensen, "A critical evaluation for a class of micromechanics models," Journal of the Mechanics and Physics of Solids, vol. 38, no. 3, pp. 379-404, 1990.

[37] P. Cawley and R. D. J. Adams, "A vibration technique for nondestructively assessing the integrity of structures," Composite Materials, vol. 12, pp. 336-347, 1978.

[38] J. M. Hodgkinson, Mechanical Testing of Advanced Fibre Composites, Woodhead Publishing, 2000.

[39] V. G. Geethamma, G. Kalaprasad, G. Groeninckx, and S. Thomas, "Dynamic mechanical behavior of short coir fiber reinforced natural rubber composites," Composites A: Applied Science and Manufacturing, vol. 36, no. 11, pp. 1499-1506, 2005.

[40] E. Sarlin, Y. Liu, M. Vippola et al., "Vibration damping properties of steel/rubber/composite hybrid structures," Composite Structures, vol. 94, no. 11, pp. 3327-3335, 2012.

[41] D. D. L. Chung, "Structural composite materials tailored for damping," Journal of Alloys and Compounds, vol. 355, no. 1-2, pp. 216-223, 2003.

[42] A. G. Piersol and T. Harris, Shock and Vibration Handbook, McGraw Hill, New York, NY, USA, 6th edition, 2010.

[43] L. Meirovitch, Analytical Methods in Vibrations by Leonard Meirovitch, 1967.

[44] J. Summerscales, Non-Destructive Testing of Fiber-Reinforced Plastics Composites, Elsevier Applied Science, London, UK, 1987.

[45] R. F. Gibson, "Modal vibration response measurements for characterization of composite materials and structures," Composites Science and Technology, vol. 60, no. 15, pp. 2769-2780, 2000.

[46] J. M. Whitney, "Shear correction factors for orthotropic laminates under static load," Journal of Applied Mechanics, vol. 40, no. 1, pp. 302-304, 1973. 


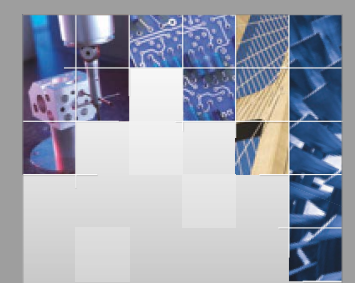

\section{Enfincering}
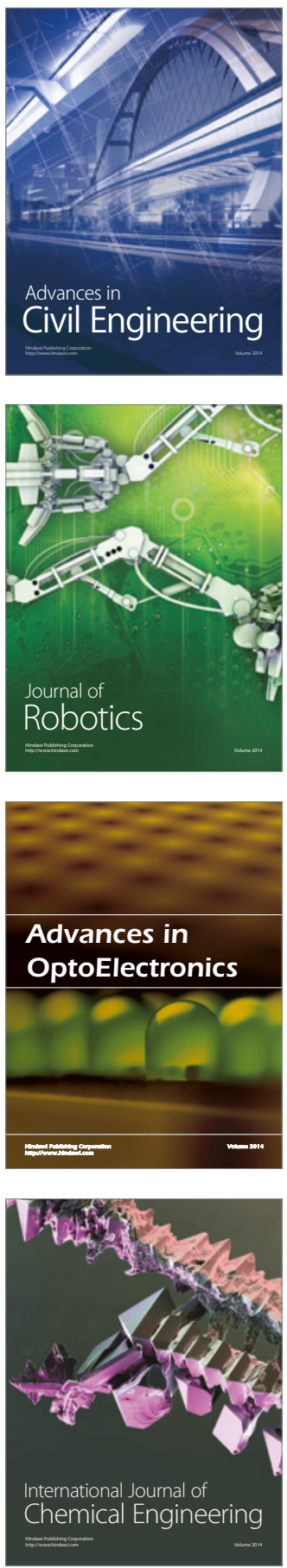

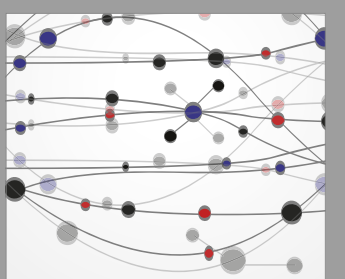

The Scientific World Journal



\section{Hindawi}

Submit your manuscripts at

https://www.hindawi.com
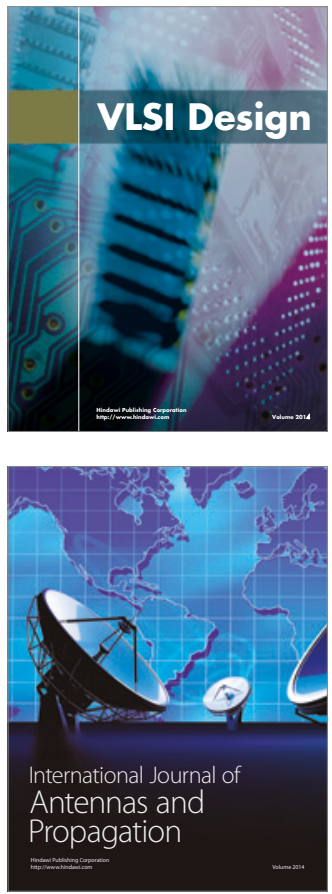

\section{Rotating}

Machinery
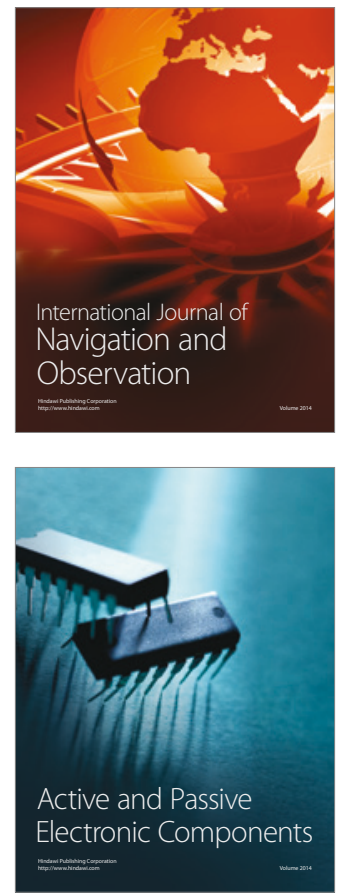
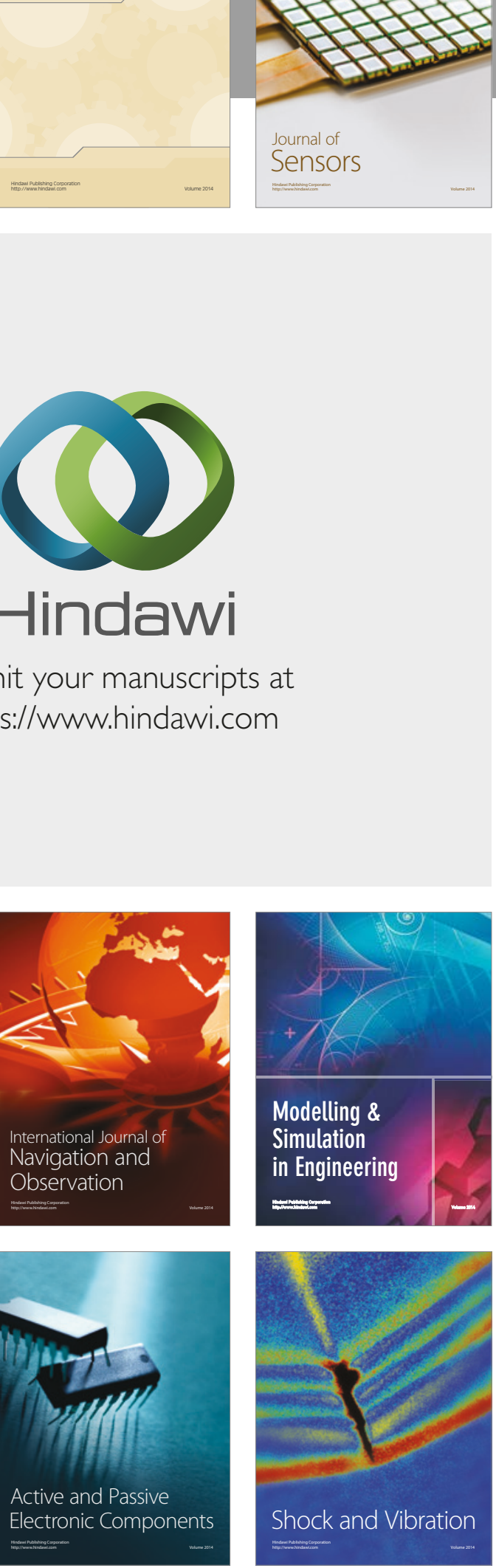
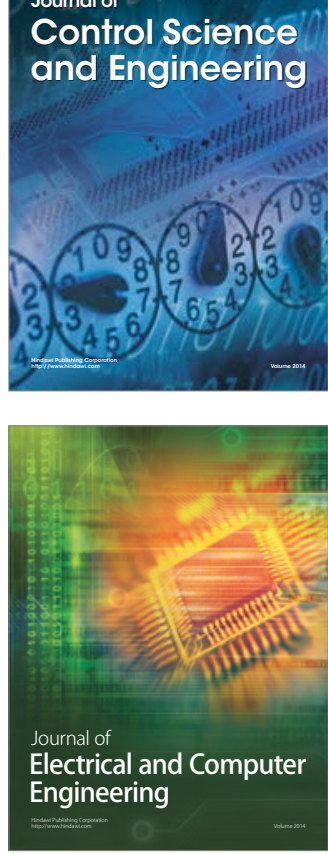

Distributed

Journal of

Control Science

and Engineering
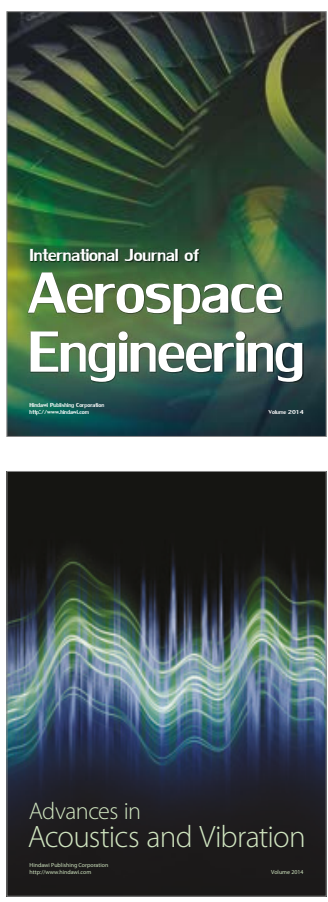

Sensor Networks 